\title{
EMERGÊNCIA DE PLÂNTULAS E ARMAZENAMENTO DE ENDOCARPOS DE Licania tomentosa (Benth.) Fritsch
}

\author{
SILVA, Josefa Jussara Rego da ${ }^{1}$ \\ SILVA, Maria Isabel Mendonça da ${ }^{2}$ \\ AZEREDO, Gilvaneide Alves ${ }^{3}$ \\ SOUZA, Vênia Camelo de ${ }^{4}$
}

RESUMO: Licania tomentosa (Benth.) Fritsch. (Oiti) é uma espécie arbórea representativa da Mata Atlântica, pertencente à família Chrysobalanaceae. Para obtenção de sementes de boa qualidade, um dos aspectos que devem ser considerados é o momento de sua coleta, que pode ser determinada pelo estádio de desenvolvimento do fruto. Quanto ao armazenamento, cada espécie possui exigências próprias para a manutenção da qualidade fisiológica de suas sementes. Os objetivos deste trabalho foram: avaliar a resposta germinativa do estádio de maturação de frutos de oiti sobre a emergência e o vigor das sementes; e o efeito do armazenamento de endocarpos de oiti em ambiente de laboratório sobre a qualidade fisiológica das sementes. Na primeira etapa, foram coletados frutos no chão em diferentes estádios de maturação (amarelo, verde-amarelado, verde e escuro-enrugado). Na segunda, os frutos amarelos foram despolpados e os endocarpos armazenados por um período de 90 dias em ambiente de laboratório. Para o primeiro ensaio, os frutos foram colocados para germinar em bandejas no substrato areia, com 10 repetições de 10 sementes, em viveiro. Para o segundo ensaio, a cada 30 dias e, antes do armazenamento (tempo zero), os endocarpos foram colocados para germinar nessas mesmas condições. Conclui-se, portanto, que frutos de oiti na coloração amarela, podem ser recomendados como adequados para coleta, pela elevada qualidade fisiológica de suas sementes. O armazenamento de endocarpos de oiti, em ambiente não controlado, foi favorável até aos 30 dias; a partir desse período, o armazenamento desses foi prejudicial à qualidade de suas sementes.

Palavras-chave: Conservação. Espécie florestal. Coloração de frutos. Vigor.

SUMMARY: Licania tomentosa (Benth.) Fritsch. (Oiti) is an arboreal species representative of Atlantic forest and belongs to Chrysobalanaceae family. In order to obtain seeds of good quality, one of the aspects that must be considered is the moment of its collect, which can be determined by the stage of development of the fruit. About storage, each species has its own requirements for the maintenance of the physiological quality of its seeds. The aims of this work were: to evaluate the germinative response of the maturation stage of Oiti fruits on the vigor of the seeds; and the effect of the storage of endocarps of Oiti in a laboratory environment on the physiological quality of its seeds. In the first step, fruits in different stadiums of maturation were collected from the ground (yellow, greenyellowish, green and dark-wrinkled). In the second step, the yellow fruits were pulped and the endocarps were stored for a period of 90 days in a laboratory environment. For the first assay, the fruits were placed to germinate in trays in sand substrate, with 10 replications of 10 seeds, in nursery. For the next assay, every 30 days and, before the storage (time zero), the endocarps were placed to germinate in these same conditions. Therefore, it is concluded, that fruits of oiti in the yellow coloration, can be recommended as adjusted for collection, for the high physiological quality of its seeds The storage of endocarps of oiti, in uncontrolled environment, was favorable until the 30 days, from this period, the storage of endocarps was harmful to the quality of its seeds.

Keywords: Conservation. Forest species. Fruit coloring. Vigor.

\section{INTRODUÇÃO}

O conhecimento da flora nativa é de vital importância não apenas como uma forma de realizar o levantamento da biodiversidade, mas, sobretudo, para desenvolver estratégias de conservação e

\footnotetext{
${ }^{1}$ Graduanda em Lic em Ciências Agrárias, CCHSA, UFPB

${ }^{2}$ Graduanda em Medicina Veterinária, UFPB, CCHSA, UFPB

${ }^{3}$ Departamento de Agricultura, CCHSA, UFPB

${ }^{4}$ Departamento de Ciências Básicas e Sociais, CCHSA, UFPB
} 
aproveitamento racional dos recursos naturais. Quando se trata de espécies florestais nativas esse conhecimento é geralmente escasso, principalmente no que se refere a protocolos envolvendo conservação de sementes. A propagação de espécies nativas vem sendo estudada por diferentes pesquisadores e o interesse por essas espécies vem crescendo a cada dia, devido à atenção focada, cada vez mais, nos problemas ambientais, com vistas à produção de mudas para recuperar e, ou enriquecer áreas degradadas resultantes da exploração desordenada dos recursos naturais.

O oiti (Licania tomentosa (Benth.) Fritsch), é uma árvore brasileira que ocorre naturalmente desde Pernambuco até o Norte do Espírito Santo e Vale do Rio Doce do estado de Minas Gerais, estando associada à floresta pluvial atlântica. Seu tronco tem madeira dura, de longa durabilidade, recomendável para a construção civil, postes, e vários outros usos. É uma espécie muito indicada para reflorestamentos mistos de áreas degradadas e também para a arborização urbana, por não possuir raízes profundas que danificam os calçamentos (LORENZI, 2009). Na literatura existem vários artigos que mostram a $L$. tomentosa como o objetivo de arborização, sendo uma ótima espécie para fornecer sombra, não necessita de grandes quantidades de água para a sua sobrevivência, ainda se adequando a espaços urbanos (ANDEL, 2001; AMARAL; MANTELLI; ROSSETI, 2011).

A época de colheita é um dos fatores mais importantes que influenciam as características de uma semente, seja de qual espécie for. O estádio de maturação, grau de umidade e danos mecânicos que podem ocorrer durante a colheita, têm uma influência decisiva na qualidade física e fisiológica da semente (SMIRDELE; DIAS, 2011). Dessa forma, colher na época certa é de fundamental importância para se obter produto de melhor qualidade e com maior rendimento. Segundo Oro et al. (2012), a coleta das sementes de Eugenia pyriformis Cambess deve ser feita entre os estádios de coloração dos frutos verde/amarelo e amarelo/laranja e no estádio de coloração dos frutos vermelho-claro em relação a Eugenia involucrata D.C. Em sementes de pinhão manso (Jatropha curcas L.) a expressão de viabilidade se dá em sementes colhidas no estádio II de maturação (frutos amarelos com sementes pretas brilhantes), onde na ocasião, seus frutos encontram-se amarelos e com sementes pretas brilhantes (PESSOA et al., 2012).

As espécies também se comportam diferentemente em função das condições de armazenamento apresentando exigências próprias para a manutenção da qualidade fisiológica, o que requer estudos específicos. A importância da temperatura e da umidade relativa do ambiente no armazenamento e suas interações são prioritárias para o entendimento das exigências da espécie quanto à manutenção da viabilidade (SANGALLI et al., 2012).

O armazenamento de sementes significa conservar sementes obtidas numa determinada ocasião, procurando manter a sua máxima qualidade fisiológica, física, e sanitária, retardando ao máximo seu envelhecimento (deterioração), objetivando seu uso no futuro. Durante o armazenamento, esse processo irreversível que é o envelhecimento da semente, envolve alterações fisiológicas, bioquímicas e físicas, contudo a velocidade do processo pode ser minimizada por meio de procedimentos adequados de produção, colheita, beneficiamento, transporte e armazenamento (MEDEIROS, 2001; VILLELA; PERES, 2004; MARCOS FILHO, 2005; SENA, 2008).

Considerando o armazenamento como o conjunto de condições e técnicas que diminuem a velocidade de processos de deterioração de sementes entre a colheita e a semeadura, duas condições ambientais são básicas para a manutenção da viabilidade de sementes florestais durante o armazenamento: umidade e temperatura. Sendo que o tempo em que a semente vai ficar armazenada vai depender do planejamento do uso futuro dessas sementes. Onde o período curto seria o de seis meses, médio de até cinco anos e como período longo mais de cinco anos (FOWLER; MARTINS, 2001).

São escassos trabalhos que associem maturação dos seus frutos e a viabilidade das sementes como também aspectos relacionados à conservação de sementes. Portanto, é de suma importância que se 
desenvolvam pesquisas neste sentido, visando dar uma contribuição significativa a tecnologistas de sementes quanto a capacidade germinativa dessa espécie e do potencial de armazenamento de suas sementes. Diante do exposto, este trabalho teve como finalidade avaliar a resposta de estádios de maturação dos frutos sobre a emergência e o vigor das sementes de oiti, bem como o efeito do armazenamento do endocarpo sobre a qualidade fisiológica de suas sementes por um período de 90 dias em ambiente não controlado de laboratório.

\section{MATERIAL E MÉTODO}

Foram conduzidos dois ensaios desenvolvidos no Viveiro de Produção de Mudas do CCHSA/UFPB, Campus de Bananeiras-PB. Os frutos de oiti foram coletados no chão em abril/2013, em oito indivíduos existentes no Campus III. Para o primeiro ensaio experimental, após coleta, os frutos foram classificados em quatro categorias: amarelo (recém-caídos), verde-amarelado, verde e escuro enrugado (este último, frutos ressecados pelo sol com pericarpo endurecido). Em seguida, os endocarpos foram colocados para germinar em bandejas de dimensões 43,5 cm (comprimento) x 29,6 cm (largura) x $7,5 \mathrm{~cm}$ (altura), contendo areia lavada (granulometria média), utilizando 10 repetições de 10 frutos. Foram avaliadas as seguintes características: emergência, índice de velocidade de emergência, tempo médio de emergência e velocidade média de emergência.

No segundo ensaio, os frutos amarelos foram despolpados no Laboratório de Sementes, com o auxílio de uma peneira e água corrente e, após uma semana, sobre papel toalha, os endocarpos foram separados (para cada período de armazenamento) e armazenados em ambiente natural de laboratório (condições não controladas), utilizando-se sacos plásticos transparentes com dimensões $35 \mathrm{~cm}$ x $50 \mathrm{~cm}$ x $0,20 \mathrm{~cm}$, por um período de $0,30,60$ e 90 dias. A escolha desta coloração de fruto foi feita em função dos resultados obtidos no primeiro ensaio. $\mathrm{O}$ armazenamento foi feito com endocarpos face às dificuldades em extrair as sementes no interior destes. Antes (controle) e após cada período de armazenamento, foram avaliadas as seguintes características: teor de água (BRASIL, 2009) com duas amostras de cinco endocarpos; emergência de plântulas (E); índice de velocidade de emergência; tempo médio de emergência (TME); e velocidade média de emergência (VME).

Para a semeadura, em ambos os ensaios, os endocarpos foram colocados em bandejas contendo o substrato areia, utilizando-se 10 repetições de 10 endocarpos, totalizando 100 unidades. As leituras foram feitas diariamente, assim que foi observado o início da emergência sobre o substrato, estendendo-se por um período de 75 dias após a semeadura para cada período de armazenamento.

Para o primeiro ensaio, o delineamento estatístico utilizado foi inteiramente casualizado e as médias foram comparadas pelo teste de Tukey a 5\% de probabilidade pelo Teste de Tukey. No segundo, os dados quantitativos relacionados aos períodos de armazenamento foram submetidos à análise de regressão polinomial, utilizando o programa estatístico ESTAT/Jaboticabal (1994).

\section{RESULTADO E DISCUSSÃO}

Na Tabela 1 observa-se a análise de variância para o primeiro ensaio experimental e constata-se significância a $1 \%$ de probabilidade para todas as variáveis com exceção da emergência cujo efeito não foi significativo. 
Tabela 1. Análise de variância para emergência, índice de velocidade de emergência (IVE), tempo médio de emergência (TME) e velocidade média de emergência (VME) de endocarpos de Licania tomentosa L. provenientes de frutos em diferentes estádios de maturação.

\begin{tabular}{lcccc}
\hline Fontes de & \multicolumn{4}{c}{ Quadrados Médios } \\
\cline { 2 - 5 } variação & Emergência & IVE & TME & VME \\
\hline Tratamentos & $150,00^{\mathrm{ns}}$ & $0,0178^{* *}$ & $95,36^{* *}$ & $0,000^{* *}$ \\
Resíduo & 81,66 & 0,0377 & 7,19 & 0,000 \\
\hline Média & 90,50 & 0,2259 & 40,49 & 0,0243 \\
CV $(\%)$ & 9,99 & 14,43 & 6,62 & 8,28 \\
\hline
\end{tabular}

** significativo a $1 \%$ de probabilidade pelo teste $\mathrm{F} .{ }^{\text {ns }}$ - não significativo

Fonte: Elaborado pelo autor

Na Tabela 2, não houve efeito significativo dos estádios de maturação sobre a emergência de plântulas. Todos os tratamentos proporcionaram elevados percentuais de emergência acima de $85 \%$, apresentando maior valor absoluto aqueles de coloração amarela com 95\% de emergência. Isacksson (2015), objetivando conhecer a germinação de sementes contidas nos endocarpos de espécies do mesmo gênero (Licania macrophylla Benth. e Licania heteromorpha Benth.), verificou que a porcentagem de germinação foi de 100\% para ambas as espécies. Para Silva et al. (2013a), a capacidade germinativa de sementes de oiti-coró (Couepia rufa Ducke) foi também de 100\% no tratamento com substrato vermiculita ao final dos 150 dias. Já para Lorenzi $(2008,2009)$ a emergência de parte aérea ocorreu entre 10 a 20 dias para L. tomentosa com porcentagem de germinação superior a $90 \%$ e, para L. salzmannii (Hook. f.) Fritsch, foi maior que $80 \%$. Alves e Passoni (1997), trabalhando com sementes de oiti, verificaram efeito favorável de compostos orgânicos sobre a percentagem de germinação dessas sementes em relação a testemunha. Aos 30 dias após a semeadura, obtiveram mais de 50\% de germinação e aos 150 dias, até $100 \%$.

Em relação ao IVE, o estádio de maturação amarelo alcançou o maior índice de velocidade de emergência, diferindo estatisticamente apenas do tratamento escuro-enrugado. Comportamento similar foi observado para a VME aonde se observa que os frutos verde-amarelado e o escuro-enrugado diferiram dos frutos de coloração amarela. Em relação ao TME, o tratamento que requereu mais dias para que as plântulas emergissem foi o escuro-enrugado com 44 dias. O menor valor de TME foi obtido no tratamento amarelo (37 dias), apesar deste não ter diferido do verde e do verde-amarelado. Percebe-se, portanto, dentre os estádios de maturação testados, que os frutos escuros enrugados tiveram menor emergência e vigor em relação aos demais tratamentos no tocante às características avaliadas neste trabalho, possivelmente por estarem ressecados ao sol e com o pericarpo endurecido e sujeitos a ação de microrganismos e a outros fatores externos.

Isacksson (2015) encontrou para Licania macrophylla um tempo médio de germinação em torno de 48,3 dias e IVG de 0,2. Para a formação de plântulas dessa espécie, o TMG encontrado foi de 59,8 dias e o IVG de 0,2. Pode-se notar que a emergência de plântulas do oiti é lenta e desuniforme. Esta espécie apresenta germinação do tipo hipógea e segundo Parolin et al. (2003) espécies que apresentavam germinação hipógea levaram mais tempo para germinar do que as espécies com germinação epígea. 
Tabela 2. Efeito de diferentes estádios de maturação de frutos de Licania tomentosa L. sobre a emergência (E), índice de velocidade de emergência (IVE), tempo médio de emergência (TME) e velocidade média de emergência (VME) de plântulas.

\begin{tabular}{lcccc}
\cline { 2 - 5 } Estádios de & \multicolumn{4}{c}{ Variáveis } \\
\cline { 2 - 5 } maturação & Emergência (\%) & IVE & TME (dias) & VME \\
\hline Amarelo & $95 \mathrm{a}$ & $0,25 \mathrm{a}$ & $37,06 \mathrm{~b}$ & $0,0268 \mathrm{a}$ \\
Verde-amarelado & $89 \mathrm{a}$ & $0,22 \mathrm{ab}$ & $40,23 \mathrm{~b}$ & $0,0239 \mathrm{bc}$ \\
Verde & $92 \mathrm{a}$ & $0,22 \mathrm{ab}$ & $40,13 \mathrm{~b}$ & $0,0246 \mathrm{ab}$ \\
Escuro-enrugado & $86 \mathrm{a}$ & $0,19 \mathrm{~b}$ & $44,57 \mathrm{a}$ & $0,0219 \mathrm{c}$ \\
\hline CV $(\%)$ & 9,9 & 14,43 & 6,62 & 8,28 \\
\hline
\end{tabular}

Médias seguidas pela mesma letra minúscula na coluna não diferem significativamente entre si pelo teste de Tukey a $5 \%$ de probabilidade.

Fonte: Elaborado pelo autor

Quanto ao segundo ensaio experimental não houve medição da temperatura e da UR do ar no local de armazenamento dos endocarpos durante os meses de março a junho de 2013. Os dados foram adquiridos por meio de consulta ao Banco de Dados Meteorológicos (BDMEP), do Instituto Nacional de Meteorologia no período em questão, de acordo com as Figuras 1 e 2.

Nos meses de março a junho de 2013 , a temperatura máxima variou de 21 a $26^{\circ} \mathrm{C}$, a mínima de 20 a $22^{\circ} \mathrm{C}$ e a média de 21 a $25^{\circ} \mathrm{C}$ (Figura 1). Em relação aos dados de umidade relativa do ar (Figura 2), a máxima variou de 93 a 99\%, a mínima de 91 a 92\% e a média de 92 a 98\% durante o período em que ocorreu o armazenamento dos endocarpos de Licania tomentosa no ambiente de laboratório. De acordo com os dados apresentados nas Figuras 1 e 2, ocorreu um decréscimo da temperatura do ar e um aumento da URar, durante o período de armazenamento, o que favoreceu a manutenção do teor de água dos endocarpos em torno de $40 \%$.

Figura 1. Temperatura do ar (máxima, média e mínima) referente aos meses de março (período zero), abril (período de 30 dias), maio (período de 60 dias) e junho (período de 90 dias) de 2013 na cidade de Bananeiras, PB.

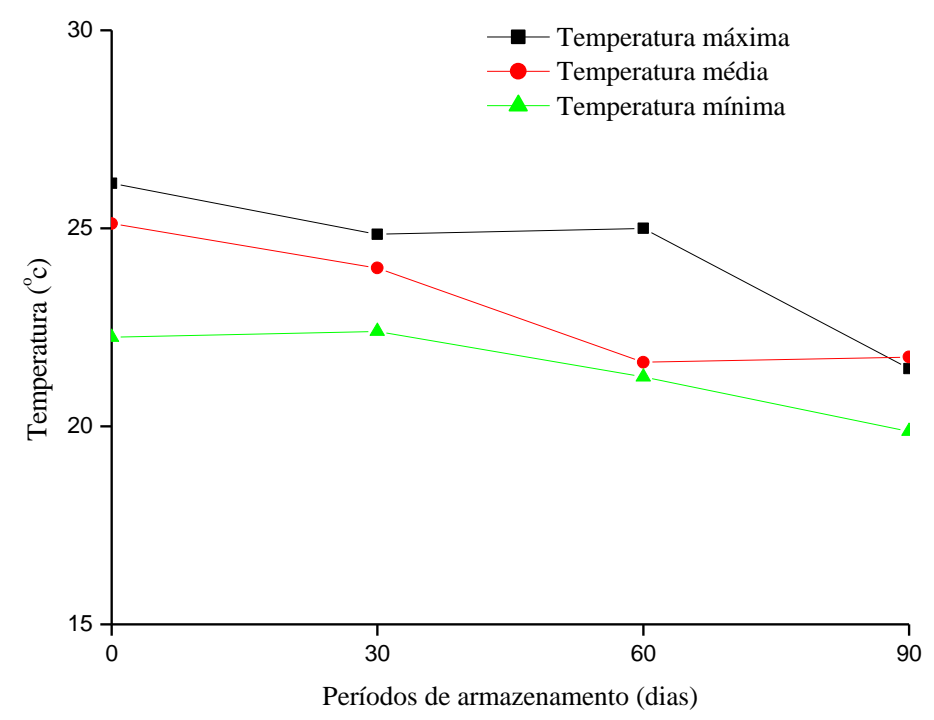

Fonte: Elaborado pelo autor 
Figura 2. Umidade relativa do ar (máxima, média e mínima) referente aos meses de março (período zero), abril (período de 30 dias), maio (período de 60 dias) e junho (período de 90 dias) de 2013 na cidade de Bananeiras, PB.

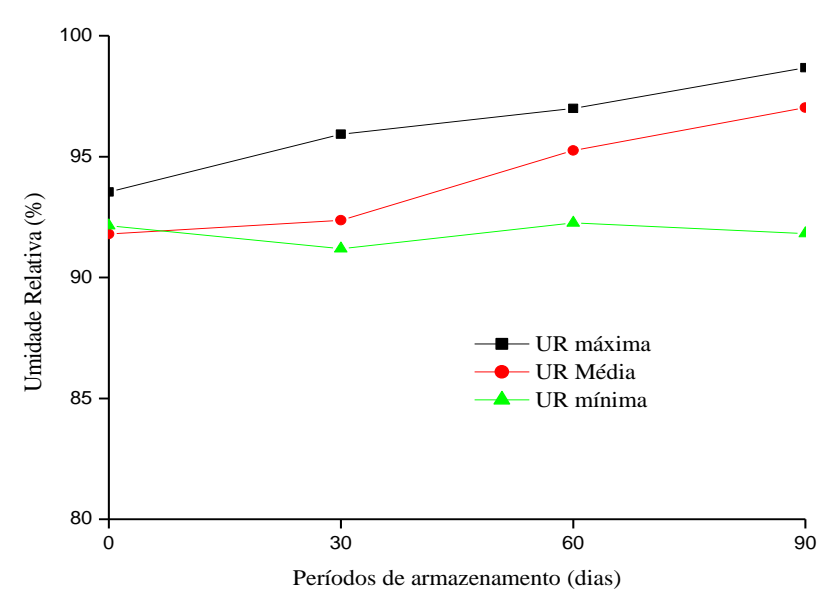

Fonte: Elaborado pelo autor

Os dados do teor de água dos endocarpos, antes e após o armazenamento, variaram de 40 a $41 \%$, ou seja, não houve praticamente variação durante o período de condução do experimento. Os endocarpos, mesmo tendo ficado a sombra por uma semana após o despolpamento dos frutos, para que ocorresse o processo de secagem natural, seu teor de água permaneceu elevado durante os 90 dias de armazenamento.

Pode-se perceber um comportamento quadrático dos dados de emergência de plântulas de oiti com um $\mathrm{R}^{2}$ de 0,99 (Figura 4). No tempo zero, a taxa de emergência situou-se em torno de $80 \%$; aos 30 dias alcançou valores acima de $60 \%$ e, a partir daí, o decréscimo foi mais acentuado, atingindo valores abaixo de $15 \%$ de emergência aos 90 dias. Sementes de Licania tomentosa, armazenadas por um período de 60 dias, conservaram-se melhor em ambiente natural do que em câmara fria, onde se registrou uma redução drástica da qualidade fisiológica das mesmas, segundo Silva et al. (2009). As sementes de oiti, segundo esses autores, apresentaram, em ambiente natural, um porcentual inicial de emergência de 73,6\% e aos 30 dias e 60 dias, em torno de 70\%, ou seja, a viabilidade foi mantida ao longo do armazenamento. Já no ambiente de câmara fria houve redução brusca, já a partir dos 30 dias, de 26\% para 0\%, aos 60 dias.

Figura 4. Emergência de plântulas de oiti (Licania tomentosa) provenientes de frutos despolpados e armazenados por um período de 90 dias em ambiente não controlado.

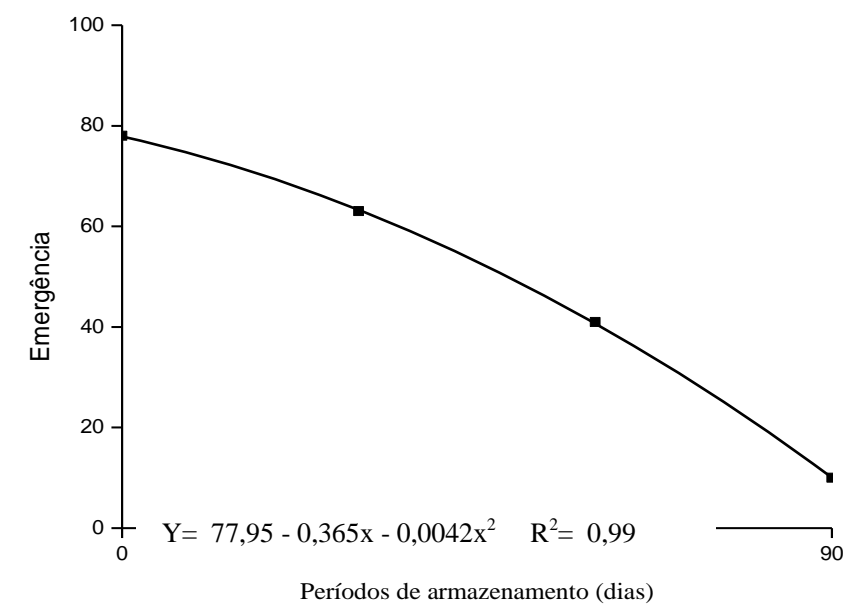

Fonte: Elaborado pelo autor 
Borba-Filho et al. (2009), por sua vez, destacam que sementes de Tabebuia roseo-alba apresentaram redução da velocidade de germinação, verificada aos 60 dias de armazenamento quando embaladas em sacos de polietileno e armazenadas em câmara refrigerada. Wielewicki et al. (2006) comentam que é essencial conhecer o comportamento fisiológico das sementes para que se possa definir a técnica apropriada para seu armazenamento seguro. Esse aspecto torna-se mais importante quando se depara com as espécies nativas que ainda não possuem metodologia para seu armazenamento, a longo prazo, como é o caso do oiti.

Os dados do índice de velocidade de emergência de plântulas de oiti são apresentados na Figura 5. Observou-se uma tendência de acréscimo do IVE (de 0,15 a 0,17), do tempo zero até os 30 dias, respectivamente, passando a decrescer acentuadamente, atingindo um IVE de 0,037 no final do período. Ou seja, a perda de vigor das sementes de oiti quando armazenadas foi evidente, mesmo por um período relativamente curto.

Figura 5. Índice de velocidade de emergência de plântulas de oiti (Licania tomentosa) provenientes de frutos despolpados e armazenados por um período de 90 dias em ambiente não controlado.

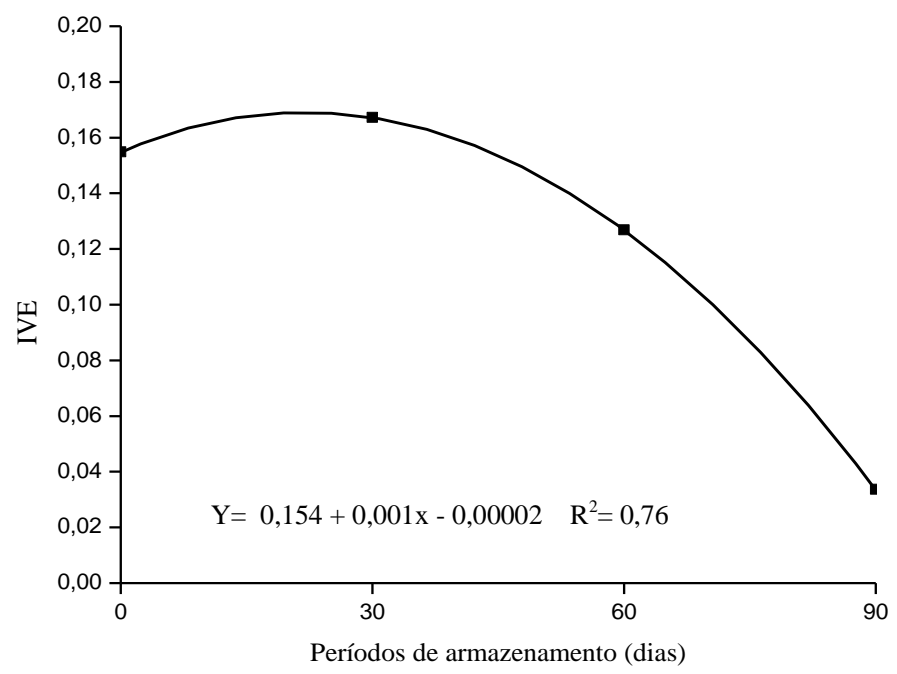

Fonte: Elaborado pelo autor

A Figura 6 diz respeito ao TME e observa-se que antes do armazenamento (tempo zero) o TME de plântulas foi de 45 dias; aos 30 dias ocorreu uma redução (em torno de 32 dias). Em seguida, verificou-se um acréscimo, culminando com um TME superior a 50 dias para que as plântulas de oiti emergissem. De acordo com Isacksson et al. (2013), o tempo médio de germinação para as sementes de Licania macrophylla foi de 58 dias e para a formação de plântulas o TMG foi de 71 dias. Para a espécie Licania heteromorfa, o TMG foi de 44,2 dias e para a formação de plântulas de 67,8 dias (ISACKSSON, 2015). Essas duas espécies pertencem a família Chrysobalanaceae, a mesma família do oiti, e é constatado um comportamento similar em relação ao tempo médio de emergência de plântulas, possivelmente em função das camadas que envolvem esses frutos, os quais são carnosos, com pericarpo frequentemente dividido em mesocarpo carnoso a madeiroso rígido e endocarpo fibroso, dando proteção ao eixo embrionário 
Figura 6. Tempo médio de emergência (TME) de plântulas de oiti (Licania tomentosa) provenientes de frutos despolpados e armazenados por um período de 90 dias em ambiente não controlado.

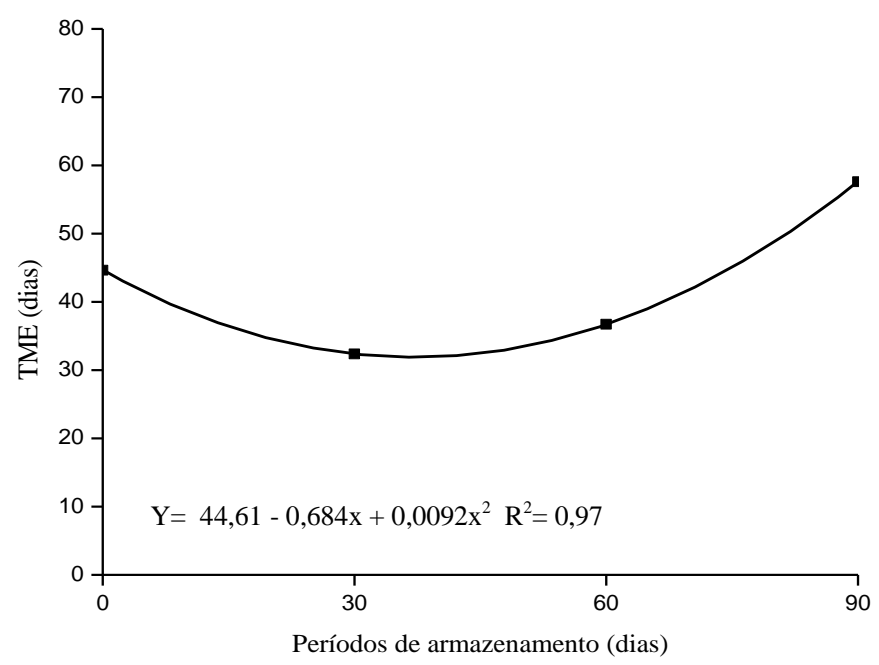

Fonte: Elaborado pelo autor

Em relação a velocidade média de emergência (Figura 7) observa-se aumento nos valores desta variável aos 30 e 60 dias em relação ao tempo inicial (zero), concordando com o menor tempo médio de emergência verificado nesses mesmos períodos (Figura 5); aos 90 dias, verificou-se redução bastante acentuada na VME e maior TME (Figura 5) nesse mesmo período. Os dados da VME e TME se complementam uma vez que a velocidade média de germinação é 1/TME.

Figura 7. Velocidade média de emergência de plântulas de oiti (Licania tomentosa) provenientes de frutos despolpados e armazenados por um período de 90 dias em ambiente não controlado.

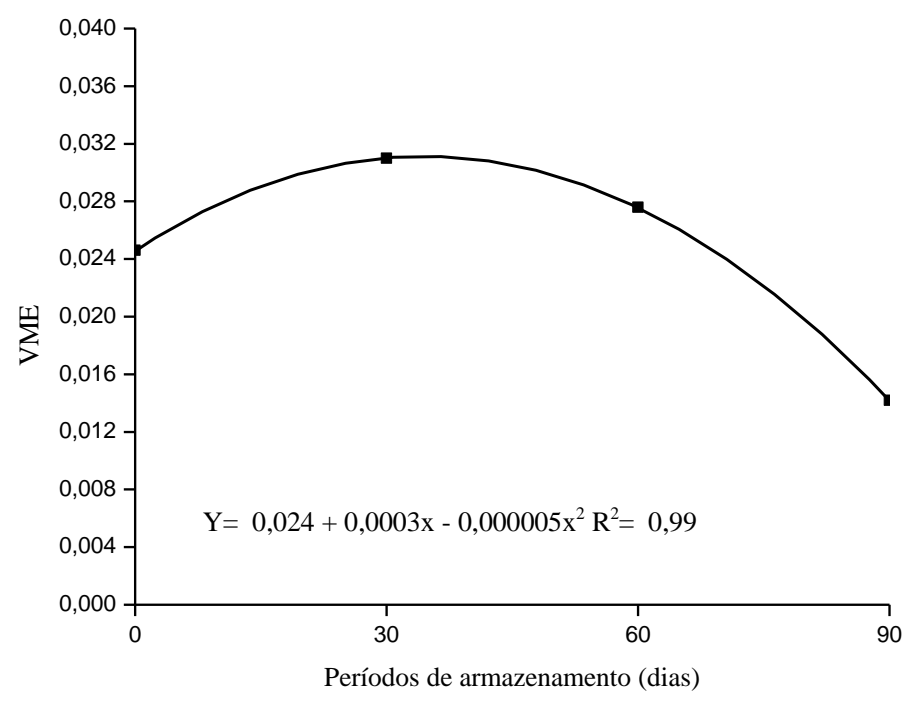

Fonte: Elaborado pelo autor

Como mencionado anteriormente, é quase inexistente, no levantamento bibliográfico efetuado, o desenvolvimento de pesquisas, envolvendo sementes de Licania tomentosa, seja com armazenamento, seja relacionando estádio de maturação e emergência de plântulas. Diante destes resultados, sugere-se que 
novas pesquisas sejam iniciadas com a espécie em questão, pela relevância que o oiti representa para a flora brasileira, a fim de investigar métodos de armazenamento (embalagem e condições de conservação) que melhor assegurem a qualidade fisiológica de suas sementes.

\section{CONCLUSÃO}

Conclui-se, portanto, que frutos de oiti na coloração amarela, podem ser recomendados como adequados para coleta, pela elevada qualidade fisiológica de suas sementes. O armazenamento de endocarpos de oiti, em ambiente não controlado de laboratório, foi favorável até aos 30 dias; a partir desse período, o armazenamento de endocarpos é prejudicial à qualidade de suas sementes.

\section{REFERÊNCIAS}

ALVES, W. L.; PASSONI, A. A. Composto e vermicomposto de lixo urbano na produção de mudas de oiti (Licania tomentosa (Benth) para arborização. Pesquisa Agropecuária Brasileira, Brasília, v. 32, n. 10, p. 58-62, 1997. https://ainfo.cnptia.embrapa.br/digital/bitstream/item/108672/1/COMPOSTO.pdf

AMARAL, D. D.; MANTELLI, L. R.; ROSSETTI, D. F. Palaeonenvironmental controlo n modern Forest composition of southwestern Marajó Island, Eastern Amazonia. Water and Environment Journal, v. 20, n. 1, p. 70-84, 2011.

ANDEL, T. V. Floristic composition and diversity of mixed primary and secondary forests in northwest Guyana. Biodiversity and Conservation, Berlin, v. 10, p. 1645-1682, 2001. https://link.springer.com/article/10.1023/A:1012069717077.

BORBA-FILHO, A. B.; PEREZ, S. C. J. G. A. Armazenamento de sementes de ipê-branco e ipê-roxo em diferentes embalagens e ambientes. Revista Brasileira de Sementes, Londrina, v. 31, n. 1, p. 259-269, 2009. http://www.scielo.br/scielo.php?script=sci_arttext\&pid=S0101-31222009000100029

BRASIL. Ministério da Agricultura, Pecuária e Abastecimento. Regras para análise de sementes. Secretaria de Defesa Agropecuária. Brasília: MAPA/ACS, 2009. 395 p.

ESTAT - Sistema de Análises Estatísticas. Universidade Estadual Paulista "Júlio de Mesquita Filho". Departamento de Ciências Exatas. ESTAT. Versão 2.0. Jaboticabal: FCAV/UNESP, 1994.

FOWLER, J. A. P.; MARTINS, E. G. Manejo de sementes de espécies florestais. Colombo: Embrapa Florestas, 2001.

ISACKSSON, J. G. L. Árvores, propágulos e plântulas de duas Licania spp. (Chrysobalanaceae) nativas da floresta de várzea estuarina. Monografia (Universidade do Estado do Amapá) - Macapá, 2015. http://www.bibliotekevirtual.org/index.php/2013-02-07-03-02-35/monografia/1383-i/14516arvores-propagulos-e-plantulas-de-duas-licania-spp-chrysobalanaceae-nativas-da-floresta-de-varzeaestuarina-amapa.html

ISACKSSON, J. G. L.et al. Germinação e morfologia de plântulas de Licania macrophylla (Crhysobalanaceae), nativa da Floresta de Várzea do Estuário, Amapá, Brasil. In: CONGRESSO NACIONAL DE BOTÂNICA, 64, Belo Horizonte. Anais...10-15 de Novembro de 2013. https://ainfo.cnptia.embrapa.br/digital/bitstream/item/95093/1/CPAF-AP-2013-Germinacao-e-morfologiaLicania.pdf

LORENZI, H. Árvores Brasileiras: manual de identificação e cultivo de plantas arbóreas nativas do Brasil. 5. ed. Nova Odessa: Instituto Plantarum. 2008. v. 1, 384 p. 
LORENZI, H. Árvores brasileiras: manual de identificação e cultivo de plantas arbóreas nativas do Brasil. Nova Odessa: Instituto Plantarum, 2009. v. 3, 384 p. il.

MARCOS FILHO, J. Fisiologia de sementes de plantas cultivadas. Piracicaba: FEALQ, 2005. 495 p.

MEDEIROS, A. C. S. Armazenamento de Sementes de Espécies Florestais. Colombo: Embrapa Florestas, 2001. 24 p. (Documentos, 66).

ORO, P. et al.Maturação fisiológica de sementes de Eugenia pyriformis Cambess e Eugenia involucrata DC. Biotemas, Florianópolis, v. 25, n. 3, p. 11-18, 2012. https://periodicos.ufsc.br/index.php/biotemas/article/view/2175-7925.2012v25n3p11

PAROLIN, P.; FERREIRA, L. V.; JUNK, W. J. Germination characteristics and establishment of trees from central Amazonian flood plains. Tropical Ecology, v. 44, n. 2, p. 157-169, 2003.

http://www.tropecol.com/pdf/open/PDF_44_2/44203.pdf

PESSOA, M. S. et al.Influência da maturação de frutos na germinação, vigor e teor de óleo de sementes de pinhão-manso (Jatropha curcas L.). Scientia Plena, Aracajú, v. 8, n. 7, 2012.

https://www.scientiaplena.org.br/sp/article/view/407

SANGALLI, A.et al. Morfometria de frutos e sementes e germinação de carobinha (Jacaranda decurrens subsp. symmetrifoliolata Farias \& Proença), após o armazenamento. Revista Brasileira de Plantas Medicinais, Botucatu, v. 14, n. 2, p. 267-275, 2012. http://www.scielo.br/scielo.php?pid=S1516$\underline{05722012000200003 \& \text { script }=\text { sci abstract } \& \text { tlng }=\text { pt }}$

SENA, C. M. Sementes Florestais: colheita, beneficiamento e armazenamento. Unidade de Apoio do PNF no Nordeste. Natal: MMA, 2008. 28 p. (Guias Técnicos, 2).

SILVA, J. J. P.et al. Metodologia para a condução do teste de germinação em sementes de oiti-coró (Couepia rufa Ducke - Chrysobalanaceae). In: CONGRESSO NACIONAL DE BOTÂNICA, 64, Anais... Belo Horizonte, 2013a. http://www.botanica.org.br/trabalhos-cientificos. php? evento $=63 \mathrm{CNB}$ ot $\&$ pagi $\mathrm{pg}=83$

SILVA, M. I. M. da.et al. Influência do estádio de maturação dos frutos de Licania tomentosa na emergência de sementes e crescimento inicial das plântulas. In: CONGRESSO NACIONAL DE BOTÂNICA, 64, Anais...Belo Horizonte, 2013b. https://www.botanica.org.br/trabalhos-cientificos/ 64CNBot/resumo-ins19024-id4253.pdf.

SILVA, M. L. M. et al. Armazenamento de sementes de Licania tomentosa (Benth.) Fritsch. em dois ambientes. In: CONGRESSO NORDESTINO DE ENGENHARIA FLORESTAL, 2., Anais...2009, Campina Grande-PB, 2009.

SMIRDELE, O. J.; DIAS, C. T. dos S. Época de colheita e armazenamento de sementes de arroz produzidas no cerrado de Roraima. Revista Agroambiente, Boa Vista, v. 5, n. 1, p. 18-23, 2011. http://revista.ufrr.br/agroambiente/article/view/383

VILLELA, F. A.; PERES, W. B. Coleta, beneficiamento e armazenamento. In: FERREIRA, A. G.; BORGHETTI, F. (Ed.). Germinação: do básico ao aplicado. Porto Alegre: Artmed, 2004. p. 149-162.

WIELEWICKI, A. P.et al. Proposta de padrões de germinação e teor de água para sementes de algumas espécies florestais presentes na região sul do Brasil. Revista Brasileira de Sementes, Londrina, v. 28, n. 3, p. 191-197, 2006. http://www.scielo.br/scielo.php?pid=S0101-

$\underline{31222006000300027 \& \text { script }=\text { sci abstract\&tlng }=\text { pt }}$ 